\title{
Vegetation changes and water cycle in a changing environment
}

\author{
Lixin Wang ${ }^{1}$, Xiaohua Wei ${ }^{2}$, Kevin Bishop ${ }^{3}$, Alison D. Reeves ${ }^{4}$, Nadia Ursino ${ }^{5}$, and Rita Winkler ${ }^{6}$ \\ ${ }^{1}$ Department of Earth Sciences, Indiana University-Purdue University Indianapolis (IUPUI), Indianapolis, IN 46202, USA \\ ${ }^{2}$ Earth, Environmental and Geographical Sciences, University of British Columbia (Okanagan campus), \\ 1177 Research Road, Kelowna, BC, Canada V1V 1V7 \\ ${ }^{3}$ Department of Aquatic Sciences and Assessment, Swedish University of Agricultural Sciences, Uppsala, Sweden \\ ${ }^{4}$ School of Social Sciences, University of Dundee, Nethergate, Dundee, UK \\ ${ }^{5}$ Dept. ICEA, Universitá di Padova, Padua, Italy \\ ${ }^{6}$ Ministry of Forests, Lands and Natural Resource Operations, Kamloops, British Columbia, Canada
}

Correspondence: Lixin Wang (lxwang @iupui.edu)

Received: 6 February 2018 - Published: 8 March 2018

Vegetation plays a vital role in the global hydrological cycle, water supply and aquatic functions. How vegetation responds to future environmental change poses one of the largest uncertainties in climate model predictions. Disturbance, both natural (e.g., wildfire, insect outbreaks, disease, windstorms, drought) and anthropogenic (e.g., timber harvesting, land conversion), can have a profound effect on hydrological processes through the impacts on vegetation dynamics. With climate change, natural disturbances are becoming more frequent and catastrophic. This, together with growing human disturbance, will undoubtedly affect water resources and consequently have significant implications for land managers and policy makers.

Ecohydrology is a science dealing with the interactions between ecosystems and hydrological processes, and many recent ecohydrological studies have focused on climate-soilvegetation interactions in both natural and managed systems (e.g., Rodriguez-Iturbe, 2000; D'Odorico et al., 2010; Wang et al., 2012a). Ecohydrology has advanced rapidly in the past few decades, which is reflected in the exponential growth in the number of both publications and citations (Wang et al., 2012b). Despite such advances, a better understanding of both the mechanisms and consequences of vegetation changes for the water cycle is still required to develop effective adaptation strategies that minimize the adverse effects of hydrological alterations. This special issue assembles a collection of 13 research articles to further our understanding of hydrological responses to vegetation dynamics under accelerated environmental and land use changes.
The spatial scales of these articles range from individual plants to continent. In particular, this special issue focuses on the following four aspects of recent advances in ecohydrological science.

\section{New understanding of the consequences of anthropogenic activity induced vegetation changes on water yield}

Quantifying the impacts of vegetation changes on water yield is important to develop sound ecosystem adaptation and mitigation strategies. By examining 80 years of streamflow and vegetation data in an experimental watershed in the Coweeta Hydrologic Laboratory in North Carolina, United States, that underwent forest-grass-forest conversion, Elliott et al. (2017) found that tree species composition in a deciduous forest had a significant influence on watershed-scale evapotranspiration and water yield. They demonstrated that a shift from species with ring-porous xylem to species with diffuse-porous xylem increased vegetation water use, and in turn produced a long-term reduction in water yield. These results have implications for land areas undergoing succession with different potential trajectories. Similarly, limited research has been conducted to examine the role of watershed properties in hydrological responses in large watersheds. Based on pair-wise comparisons, Liu et al. (2016) found that reforestation of watersheds in the upper reach of the Poyang Lake watershed with subtropical evergreen broadleaved forest types in southeastern China decreased high flows but increased low flows, indicating that hydrological 
recovery through reforestation is largely dependent on watershed properties when impacts of forest change and climate are similar and comparable. This finding has implications for designing reforestation strategies. Zhao et al. (2016) conducted an empirical study to understand how oasis ecosystems, including water, natural vegetation, and cultivated land, responded to the implementation of the Ecological Water Diversion Project (EWDP) in the Heihe River in China. They found that mean daily air temperature determines broad vegetation distribution while hydrological variables were only affected in near-river-channel regions. They also found that agricultural development prevented natural vegetation recovery in the studied area. Based on these results, it was suggested that EWDP should focus on increasing water allocation and regulating regional agricultural activities to facilitate future natural vegetation restoration. Based on extensive field observations in the downstream Heihe River in China, Ding et al. (2017) found that the vegetation community coverage and diversity of the desert riparian forests peaked at 1000 and $3000 \mathrm{~m}$ from the river channel. They also found that soil moisture along with other soil properties accounted for $53.6 \%$ of the variance in vegetation indices in the desert riparian forest. The results indicate that future ecological restoration should emphasize the importance of soil factors in this area. Since desert riparian forests provide a variety of ecosystem services in arid environments and are also endangered ecosystem types, these results will facilitate conservation efforts of this community under a changing climate.

\section{New observations of large-scale changes in water and carbon cycling and their underlying drivers}

Understanding the processes controlling evapotranspiration (ET) and gross primary productivity (GPP) is essential in order to assess the impact of climate change on agro-ecosystems and develop adaptation strategies. Mo et al. (2017) used the Variable Infiltration Capacity (VIC) model to simulate annual ET and GPP from 1981 to 2013 over the North China Plain. They showed a slight increase in both ET and GPP, and illustrated relative contributions of climatic change, $\mathrm{CO}_{2}$ fertilization, and management to these changes in ET and GPP. It was concluded that agronomical improvement through genetic improvements, use of fertilizer and irrigation, pest and/or weed control was the main driver of crop productivity enhancement. They also conclude that a decline in net radiation as a result of air pollution was the principal cause of GPP decline in the summer, while increased air temperature intensified the water cycle, enhancing plant productivity in the spring season. Sun et al. (2016) linked an ecosystem service model (Water Supply and Stress Index, WaSSI) with WRF (Weather Research and Forecasting Model) downscaled climate data to evaluate future (2031-2060) changes in ET, water yield and gross primary productivity compared with the baseline period of
1979-2007 across 82773 watersheds in the conterminous United States. They found an overall increasing trend in all three variables across all the watersheds, but the responses of the three variables to climate change were highly variable between the watersheds depending on specific regions. These results are useful for policy makers and land managers in formulating appropriate watershed-specific strategies for sustaining water and carbon sources.

\section{New understanding of the effects of vegetation on stemflow, soil moisture and soil erosion}

The ecological significance of stemflow has generally been underestimated, in part because it is relatively small in amount, and also because the biotic mechanisms that affect it have not been thoroughly studied. Yuan et al. (2017) analyzed the mechanisms influencing stemflow on the leaf scale and computed stemflow yield and efficiency, using field observations at the northern Loess Plateau of China. They found that the smaller precipitation threshold required to start stemflow and the more beneficial leaf traits (e.g., a pinnate compound leaf arrangement and a large leaf area of the branches) partly explain larger and more efficient stemflow production. During the defoliated period, they found that raindrop interception on newly exposed stems also had a significant effect on stemflow yield. Soil moisture in deep soil layers is a relatively stable water resource for vegetation growth in the semi-arid Loess Plateau of China. Fang et al. (2016) focused on analyzing the variation and factors influencing deep soil moisture content based on a soil moisture survey of the Ansai watershed within the Loess Plateau of China. Their results revealed the variable characteristics of deep soil moisture and its controlling mechanisms. Also on the Loess Plateau in China, Zhou et al. (2017) found that vegetation morphology significantly influenced the stochasticity of soil erosion. The authors constructed an integrated probabilistic assessment, based on the Poisson distribution, to describe and simulate erosion stochasticity under restored vegetation. Understanding the processes highlighted by these studies is an important step toward developing vegetation restoration strategies and ensuring the sustainability of restored ecosystems.

\section{New tools and insights in ecohydrological research}

The evapotranspiration/potential evapotranspiration (AET/PET) ratio is traditionally termed the crop coefficient $(\mathrm{Kc})$. Kc has been widely used as a parameter to estimate crop water demand by water managers but has not been well examined for other types of ecosystems such as forests and other perennial vegetation. Understanding the seasonal dynamics of this variable for all ecosystems is important for projecting the ecohydrological responses to climate change and accurately quantifying water use on 
watershed to global scales. Liu et al. (2017) derived Kc for multiple vegetation types and analyzed a global eddy flux (FLUXNET) data set to better understand the environmental controls of Kc. This study extended the applications of the traditional $\mathrm{Kc}$ method from estimating crop water use to estimating AET rates for natural ecosystems. Ajami et al. (2017) investigated the nature and frequency of non-stationary hydrological response as evidenced through water balance studies over 166 anthropogenically unaffected catchments in Australia. Non-stationarity of hydrologic response is investigated through analysis of long-term trends in annual runoff ratios (1984-2005). The role of vegetation dynamics in streamflow is indicated by similar or greater sensitivity of the annual runoff ratio to annual fractional vegetation cover than to annual precipitation. The authors present the first data-based framework for explaining why catchments behave in a non-stationary manner, even when they are unaffected by deforestation or urbanization. Alpine swamp meadow is a unique grassland type in the eastern Tibetan Plateau of China and is currently undergoing severe degradation. The effects of alpine swamp meadow degradation on soil hydraulic properties and hydrologic processes are not well understood. Pan et al. (2017) show that soil hydraulic properties, especially those of the topsoil, varied greatly with alpine swamp meadow degradation. Soil porosity is the dominant factor influencing the soil hydraulic properties of these ecosystems. The results suggest that alpine swamp meadow degradation would inevitably lead to negative hydrological effects.

This volume reflects the rapid development of many aspects of ecohydrology. More importantly, these studies emphasized various important roles vegetation plays in hydrological processes across different spatial and temporal scales. It is our hope that readers will find new tools and insights for understanding ecological and hydrological processes in this volume that will help address emerging environmental issues in a changing environment.

Competing interests. The authors declare that they have no conflict of interest.

Special issue statement. This article is part of the special issue "Vegetation changes under a changing environment and the impacts on water and carbon cycling". It is not associated with a conference.

Acknowledgement. Lixin Wang acknowledges summer support from the Division of Earth Sciences of the National Science Foundation (NSF EAR-1562055 and 1554894) and from the Agriculture and Food Research Initiative program (2017-67013-26191) of the USDA National Institute of Food and Agriculture.

\section{References}

Ajami, H., Sharma, A., Band, L. E., Evans, J. P., Tuteja, N. K., Amirthanathan, G. E., and Bari, M. A.: On the non-stationarity of hydrological response in anthropogenically unaffected catchments: an Australian perspective, Hydrol. Earth Syst. Sci., 21, 281-294, https://doi.org/10.5194/hess-21-281-2017, 2017.

D’Odorico, P., Laio, F., Porporato, A., Ridolfi, L., Rinaldo, A., and Rodriguez-Iturbe, I.: Ecohydrology of terrestrial ecosystems, BioScience, 60, 898-907, 2010.

Ding, J., Zhao, W., Daryanto, S., Wang, L., Fan, H., Feng, Q., and Wang, Y.: The spatial distribution and temporal variation of desert riparian forests and their influencing factors in the downstream Heihe River basin, China, Hydrol. Earth Syst. Sci., 21 , 2405-2419, https://doi.org/10.5194/hess-21-2405-2017, 2017.

Elliott, K. J., Caldwell, P. V., Brantley, S. T., Miniat, C. F., Vose, J. M., and Swank, W. T.: Water yield following forestgrass-forest transitions, Hydrol. Earth Syst. Sci., 21, 981-997, https://doi.org/10.5194/hess-21-981-2017, 2017.

Fang, X., Zhao, W., Wang, L., Feng, Q., Ding, J., Liu, Y., and Zhang, X.: Variations of deep soil moisture under different vegetation types and influencing factors in a watershed of the Loess Plateau, China, Hydrol. Earth Syst. Sci., 20, 3309-3323, https://doi.org/10.5194/hess-20-3309-2016, 2016.

Liu, W., Wei, X., Li, Q., Fan, H., Duan, H., Wu, J., GilesHansen, K., and Zhang, H.: Hydrological recovery in two large forested watersheds of southeastern China: the importance of watershed properties in determining hydrological responses to reforestation, Hydrol. Earth Syst. Sci., 20, 4747-4756, https://doi.org/10.5194/hess-20-4747-2016, 2016.

Liu, C., Sun, G., McNulty, S. G., Noormets, A., and Fang, Y.: Environmental controls on seasonal ecosystem evapotranspiration/potential evapotranspiration ratio as determined by the global eddy flux measurements, Hydrol. Earth Syst. Sci., 21, 311-322, https://doi.org/10.5194/hess-21-311-2017, 2017.

Mo, X., Chen, X., Hu, S., Liu, S., and Xia, J.: Attributing regional trends of evapotranspiration and gross primary productivity with remote sensing: a case study in the North China Plain, Hydrol. Earth Syst. Sci., 21, 295-310, https://doi.org/10.5194/hess-21295-2017, 2017.

Pan, T., Hou, S., Wu, S., Liu, Y., Liu, Y., Zou, X., Herzberger, A., and Liu, J.: Variation of soil hydraulic properties with alpine grassland degradation in the eastern Tibetan Plateau, Hydrol. Earth Syst. Sci., 21, 2249-2261, https://doi.org/10.5194/hess-212249-2017, 2017.

Rodriguez-Iturbe, I.: Ecohydrology: a hydrologic perspective of climate-soil-vegetation dynamics, Water Resour. Res., 36, 3-9, 2000.

Sun, S., Sun, G., Cohen, E., McNulty, S. G., Caldwell, P. V., Duan, K., and Zhang, Y.: Projecting water yield and ecosystem productivity across the United States by linking an ecohydrological model to WRF dynamically downscaled climate data, Hydrol. Earth Syst. Sci., 20, 935-952, https://doi.org/10.5194/hess-20935-2016, 2016.

Wang, L., D’Odorico, P., Evans, J. P., Eldridge, D. J., McCabe, M. F., Caylor, K. K., and King, E. G.: Dryland ecohydrology and climate change: critical issues and technical advances, Hydrol. Earth Syst. Sci., 16, 2585-2603, https://doi.org/10.5194/hess-162585-2012, 2012a. 
Wang, L., Liu, J., Sun, G., Wei, X., Liu, S., and Dong, Q.: Water, climate, and vegetation: ecohydrology in a changing world, Hydrol. Earth Syst. Sci., 16, 4633-4636, https://doi.org/10.5194/hess-164633-2012, 2012b.

Yuan, C., Gao, G., and Fu, B.: Comparisons of stemflow and its bio-/abiotic influential factors between two xerophytic shrub species, Hydrol. Earth Syst. Sci., 21, 1421-1438, https://doi.org/10.5194/hess-21-1421-2017, 2017.
Zhao, Y., Wei, Y., Li, S., and Wu, B.: Downstream ecosystem responses to middle reach regulation of river discharge in the Heihe River Basin, China, Hydrol. Earth Syst. Sci., 20, 4469-4481, https://doi.org/10.5194/hess-20-4469-2016, 2016.

Zhou, J., Fu, B., Gao, G., Lü, Y., and Wang, S.: An integrated probabilistic assessment to analyse stochasticity of soil erosion in different restoration vegetation types, Hydrol. Earth Syst. Sci., 21, 1491-1514, https://doi.org/10.5194/hess-21-1491-2017, 2017. 